\title{
MODIFIKASI MODEL KONTEMPORER DAN KAUSALITAS ANTARA VOLUME PERDAGANGAN, BID-ASK SPREAD, RETURN SAHAM DAN VOLATILITAS RETURN (STUDI KASUS: INDEKS LQ-45)
}

\author{
Nina Valentika \\ Program Studi Matematika, FMIPA - UNPAM \\ email : dosen02339@unpam.ac.id
}

\begin{abstract}
A stock trading variable may be affected by stock trading variable another at the same period, itself or other stock trading variable at different period of time. This paper presents a modification of Valentika N, Nugrahani E, and Lesmana D (2017) model on Indonesian stock data with the case study of LQ-45 Index. This paper empirically examines the relationship among trading volume, bid-ask spread and stock return to volatility. Regression results show that there is insufficient evidence to support the existence of the mixture of distribution hypothesis (MDH) theory in the market. Based on the Granger causality test, this raises the notion that intraday trading of LQ-45 stock samples tends to follow the MDH theory.
\end{abstract}

Keywords: trading volume, bid-ask spread, volatility and stock return

\begin{abstract}
ABSTRAK
Suatu variabel perdagangan saham mungkin dipengaruhi oleh variabel perdagangan saham lain pada periode yang sama, variabel perdagangan saham itu sendiri maupun variabel lainnya pada periode yang berbeda. Penelitian ini menyajikan modifikasi dari model Valentika $N$, Nugrahani E and Lesmana D (2017) pada data saham Indonesia dengan studi kasus LQ-45. Penelitian ini secara empiris menguji hubungan antara volume perdagangan, bid-ask spread dan return saham terhadap volatilitas return. Hasil regresi menunjukkan bahwa tidak cukup bukti untuk mendukung teori mixture of distribution hypothesis (MDH) pada pasar. Berdasarkan uji kausalitas Granger, terdapat dugaan bahwa perdagangan intraday sampel saham LQ-45 cenderung mengikuti teori $M D H$.
\end{abstract}

Keywords: volume perdagangan, bid-ask spread, volatilitas dan return saham 


\section{STATMAT}

(Jurnal Statistik dan Matematika)

\section{PENDAHULUAN}

\subsection{Latar Belakang Masalah}

Penelitian tidak terlepas dari ilmu statistik, contohnya adalah penelitian Aden (2018) dan Valentika N, Nugrahani E dan Lesmana D (2017). Penelitian Aden (2018) menganalisis mengenai estimasi jumlah penjualan produk. Sedangkan Valentika N, Nugrahani E dan Lesmana D (2017) menganalisis hubungan antarvariabel perdagangan saham di pasar modal Indonesia. Pasar modal diartikan sebagai pasar untuk memperjualbelikan sekuritas seperti saham dan obligasi yang umumnya berumur lebih dari satu tahun (Tandelilin E: 2010: 27). Terdapat beberapa aset perdagangan pada pasar modal, yaitu saham dan obligasi. Pada penelitian ini, aset perdagangan yang diambil adalah saham. Terdapat banyak variabel yang dapat menentukan harga saham, yaitu volume perdagangan, bid-ask spread, volatilitas return dan return saham. Untuk penyederhanaan, volatilitas return dapat ditulis menjadi volatilitas.

Suatu variabel mungkin dapat dipengaruhi oleh variabel lain pada periode yang sama, variabel itu sendiri maupun variabel lainnya pada periode yang berbeda. Secara teori, keberadaan hubungan kontemporer antara volatilitas dan volume perdagangan terutama dijelaskan oleh dua hipotesis utama yang mendasari, yaitu the mixture of distribution hypothesis (MDH) dan the sequential information arrival hypothesis (SIAH) (Paital RR dan Sharma NK 2016).

- Menurut teori $\mathrm{MDH}$, volatilitas dan volume perdagangan berubah secara contemporaneous dalam merespon kedatangan informasi baru. Sedangkan, menurut teori SIAH, ada hubungan kontemporer positif antara volatilitas dan volume perdagangan. Teori SIAH juga mendukung hubungan kausal antara volume perdagangan dan volatilitas. Sedangkan, teori MDH tidak mendukung adanya hubungan kausal.

Penelitian Valentika N, Nugrahani E dan Lesmana D (2017) menganalisis hubungan kontemporer dan kausal antara volume perdagangan terhadap volatilitas, bid-ask spread terhadap volatilitas, serta return terhadap volatilitas. Metode pendugaan parameter pada penelitian Valentika, Nugrahani dan Lesmana (2017) adalah ordinary least square (OLS). Hasil regresi pada penelitian Valentika N, Nugrahani E dan Lesmana D (2017) mengindikasikan bahwa pasar Indonesia adalah tidak efisien. Selain itu, ditemukan pula bahwa perdagangan intraday sampel saham LQ-45 cenderung mengikuti teori MDH. Sedangkan, penelitian ini ingin menggunakan model hubungan kontemporer dan kausal antara volume perdagangan, bid-ask spread dan return saham terhadap volatilitas.

\subsection{Rumusan Masalah}

Berdasarkan identifikasi dan batasan masalah yang telah diuraikan di atas, selanjutnya perumusan masalah dalam penelitian ini adalah: 
STATMAT

(Jurnal Statistik dan Matematika)

Bagaimana kecenderungan perdagangan intraday sampel saham LQ-45 apakah mengikuti teori MDH atau SIAH dengan menggunakan model hubungan antara volume perdagangan, bid-ask spread dan return saham terhadap volatilitas?

\subsection{Tujuan Penelitian}

Dari rumusan masalah di atas maka penelitian ini bertujuan untuk :

Mengetahui kecenderungan perdagangan intraday sampel saham LQ-45 apakah mengikuti teori MDH atau SIAH dengan menggunakan model hubungan antara volume perdagangan, bid-ask spread dan return saham terhadap volatilitas.

\subsection{Manfaat Penelitian}

Manfaat praktis dari penelitian ini adalah untuk mengetahui kecenderungan perdagangan intraday sampel saham LQ-45 apakah mengikuti teori MDH atau SIAH. Manfaat teoritis dari penelitian ini adalah untuk digunakan bagi kemajuan dan pengembangan ilmu ekonomi sebagai bahan referensi, serta untuk pengembangan penelitian tentang hal sama pada masa selanjutnya.

\section{METODOLOGI PENELITIAN}

\subsection{Metode Penelitian}

Metode penelitian yang digunakan pada penelitian ini yaitu penelitian survei.

\subsection{Metode Penentuan Sampel}

Sampel digunakan teknik sampel purposive. Sampel-sampel yang diambil adalah saham-saham yang konsisten selama Februari 2013 sampai Februari 2016 dan mempunyai efek ARCH pada residual dari model persamaan rataan konstan, serta memenuhi asumsi model $\operatorname{GARCH}(1,0)$ atau GARCH(1,1). Pada penelitian ini, data yang digunakan adalah data intraday (data harian/data jangka pendek) sebanyak 242 hari pengamatan, yakni terhitung dari tanggal 3 Agustus 2015 sampai dengan 29 Juli 2016.

\subsection{Langkah-langkah Penelitian}

Adapun langkah-langkah pada penelitian ini adalah

1. Mengestimasi parameter pada model hubungan kontemporer dengan metode Least Square (LS).

2. Melakukan beberapa tes yang memungkinkan pendeteksian pelanggaran asumsi pada persamaan regresi, seperti: autokorelasi dengan Breusch-Godfrey Test, heteroskedastisitas dengan Breusch-Pagan-Godfrey, serta multikolinearitas dengan variance inflation factors (VIF). Atasi pelanggaran asumsi jika asumsi dilanggar. Pelanggaran asumsi autokorelasi diatasi dengan metode Cochrane-Orcutt. Pelanggaran asumsi heteroskedastisitas dengan metode White Heteroscedasticity-Consistent Standard Error \& Covariance.

3. Memeriksa kestasioneran data dalam rataan masing-masing peubah melalui Augmented Dickey-Fuller (ADF) di dalam pengujian unit root dalam kerangka uji konfirmasi. 
4. Penentuan Lag Optimal

Penentuan kandidat lag dapat dilakukan dengan melihat lag yang memiliki nilai LR (Sequential Modified Likelihood Ratio Test Statistic) terbesar, dan FPE (Final Prediction Error), AIC (Akaike Information Criterion), SC (Schwarz Information Criterion) serta HQ (Hannan-Quinn Information Criterion) terkecil. Penentuan lag optimal dengan melihat nilai adjusted $r$-squared tertinggi dari kandidat lag tersebut.

5. Melakukan pengujian kausalitas Granger pada hubungan bid-ask spread, return saham, dan volume perdagangan dengan volatilitas return saham.

\section{HASIL DAN PEMBAHASAN}

\subsection{Deskripsi Data dan Variabel}

Pada penelitian ini, daftar perusahaan saham-saham yang dikaji disajikan pada Tabel 1. Data yang digunakan dalam penelitian ini mengikuti Valentika N, Nugrahani E dan Lesmana D (2017), yaitu harga penutupan saham, volume perdagangan dan harga penutupan bid-ask yang menggunakan data harian dari 3 Agustus 2015 sampai 29 Juli 2016 untuk semua saham. Data diambil dari www.idx.co.id.

Tabel 1 Daftar Perusahaan

\begin{tabular}{lll}
\hline No & Kode saham & Nama Saham \\
\hline 1 & AALI & Astra Agro Lestari Tbk \\
2 & ASRI & Alam Sutera Realty Tbk \\
3 & BMRI & Bank Mandiri (Persero) Tbk \\
4 & CPIN & Charoen Pokphand Indonesia Tbk \\
5 & ICBP & Indofood CBP Sukses Makmur Tbk \\
6 & INDF & Indofood Sukses Makmur Tbk \\
7 & JSMR & Jasa Marga (Persero) Tbk \\
8 & KLBF & Kalbe Farma Tbk \\
9 & LPKR & Lippo Karawaci Tbk \\
10 & MNCN & Media Nusantara Citra Tbk \\
11 & SMGR & Semen Indonesia (Persero) Tbk \\
12 & UNVR & Unilever Indonesia Tbk \\
\hline & Pendefinisian variabel perdagangan mengikuti Valentika N, Nugrahani E dan Lesmana D \\
$(2017)$, seperti: &
\end{tabular}

a. Return pada waktu $t$ adalah

$$
R_{t}=\ln \left(P_{t} / P_{t-1}\right)
$$

dimana $P_{t}$ adalah harga penutupan saham pada waktu $t$. 
b. Bid-Ask Spread adalah selisih antara harga bid dan ask. Bid-ask spread pada waktu $t$ adalah

$$
S_{t}=\frac{A s k_{t}-B_{i d_{t}}}{\left[\frac{A s k_{t}+\text { Bid }_{t}}{2}\right]} .
$$

c. Volatilitas $(\sigma)$ diduga dengan model GARCH. Inisialisasi ragam dalam pendugaan GARCH pada penelitian ini diasumsikan menggunakan metode tetap yaitu kuadrat dari residual (return) observasi sebelumnya.

d. Volume perdagangan didefinisikan sebagai

$$
V_{t}=\ln \left(\operatorname{Vol}_{t}\right),
$$

dimana $\mathrm{Vol}_{t}$ adalah volume perdagangan pada waktu $t$.

\subsection{Model Kontemporer dan Kausal}

Penelitian ini menyajikan model hubungan kontemporer dan kausal antara volume perdagangan, bid-ask spread dan return saham terhadap volatilitas. Model kontemporer antara volume perdagangan, bid-ask spread dan return saham terhadap volatilitas sebagai berikut:

$$
\sigma_{t}=\alpha_{0}+\beta_{1} V_{t}+\beta_{2} S_{t}+\beta_{3} R_{t}+u_{t},
$$

dimana $R_{t}, \sigma_{t}, V_{t}$ dan $S_{t}$ adalah return saham, volatilitas, volume perdagangan dan bid-ask spread secara berturut-turut pada waktu $t$.

Hubungan kausal antara volume perdagangan, bid-ask spread dan return saham terhadap volatilitas:

$$
\begin{gathered}
\sigma_{t}=c_{1}+\sum_{i=1}^{p_{1}} \varphi_{1(i)} \sigma_{t-i}+\sum_{i=1}^{p_{2}} \varphi_{2(i)} V_{t-i}+\eta_{1 t} \\
V_{t}=c_{2}+\sum_{i=1}^{p_{3}} \varphi_{3(i)} \sigma_{t-i}+\sum_{i=1}^{p_{4}} \varphi_{4(i)} V_{t-i}+\eta_{2 t} \\
\sigma_{t}=c_{3}+\sum_{i=1}^{p_{5}} \varphi_{5(i)} \sigma_{t-i}+\sum_{i=1}^{p_{6}} \varphi_{6(i)} S_{t-i}+\eta_{3 t} \\
S_{t}=c_{4}+\sum_{i=1}^{p_{7}} \varphi_{7(i)} \sigma_{t-i}+\sum_{i=1}^{p_{8}} \varphi_{8(i)} S_{t-i}+\eta_{4 t} \\
\sigma_{t}=c_{5}+\sum_{i=1}^{p_{9}} \varphi_{9(i)} \sigma_{t-i}+\sum_{i=1}^{p_{10}} \varphi_{10(i)} R_{t-i}+\eta_{5 t} \\
R_{t}=c_{6}+\sum_{i=1}^{p_{11}} \varphi_{11(i)} \sigma_{t-i}+\sum_{i=1}^{p_{12}} \varphi_{12(i)} R_{t-i}+\eta_{6 t} .
\end{gathered}
$$

dimana $c_{k}$ adalah intersep, $\varphi_{m(i)}$ adalah parameter dan $p_{n}$ adalah panjang lag optimal, dimana $k=1,2 \ldots, 6, m=1,2, \ldots, 12$ dan $n=1,2, \ldots, 6$. 
STATMAT

(Jurnal Statistik dan Matematika)

\section{3 Hasil Implementasi Model Hubungan Kontemporer antara Volume Perdagangan,}

\section{Bid-Ask Spread dan Return Saham terhadap Volatilitas}

Pengujian untuk mendeteksi pelanggaran asumsi pada persamaan regresi pada penelitian ini, yaitu: autokorelasi dengan Breusch-Godfrey Test, heteroskedastisitas dengan Breusch-PaganGodfrey, dan multikolinearitas dengan variance inflation factors (VIF). Pada penelitian ini, metode yang digunakan dalam mengatasi pelanggaran asumsi jika terjadi pelanggaran asumsi autokorelasi, yaitu dengan metode Cochrane-Orcutt. Sedangkan, jika terjadi pelanggaran asumsi heteroskedastisitas, diatasi dengan metode White Heteroscedasticity-Consistent Standard Error \& Covariance.

Model hubungan kontemporer antara volume perdagangan, bid-ask spread dan return saham terhadap volatilitas pada persamaan (1). Hubungan kontemporer antara volume perdagangan, bid-ask spread dan return saham terhadap volatilitas disajikan pada Tabel 2. Parameter $\beta$ mengukur hubungan kontemporer.

Tabel 2 Hubungan kontemporer volume perdagangan, bid-ask spread, return saham terhadap volatilitas

\begin{tabular}{lccccl}
\hline Kode Saham & $\alpha_{0}$ & $\beta_{1}$ & $\beta_{2}$ & $\beta_{3}$ & $R$-sq \\
\hline AALI & $0.005929^{*}$ & $-0.000898^{*}$ & 0.038714 & $-0.019598^{*}$ & 0.077725 \\
ASRI & 0.002156 & $0.001409^{*}$ & -0.306358 & $-0.027051^{*}$ & 0.048250 \\
BMRI & 0.001015 & $0.001220^{*}$ & -0.065093 & 0.005118 & 0.018575 \\
CPIN & $0.003798^{*}$ & -0.000474 & -0.038773 & 0.003732 & 0.015050 \\
ICBP & $0.003738^{*}$ & 0.000231 & -0.016582 & $-0.047711^{*}$ & 0.094479 \\
INDF & $0.001135^{*}$ & $-0.000286^{*}$ & $-0.059849 *$ & 0.000370 & 0.065584 \\
JSMR & -0.007566 & $0.001894^{*}$ & -0.037994 & 0.027009 & 0.096965 \\
KLBF & -0.014978 & $0.002197^{*}$ & 0.092133 & 0.001690 & 0.077382 \\
LPKR & -0.006810 & $0.001548^{*}$ & 0.123129 & -0.017816 & 0.043561 \\
MNCN & $0.006219 *$ & $-0.000932^{*}$ & 0.040845 & -0.006536 & 0.053990 \\
SMGR & $0.002337^{*}$ & $-0.000710^{*}$ & 0.014176 & $-2.14 \mathrm{E}-05$ & 0.036200 \\
UNVR & $0.009566^{*}$ & -0.000313 & -0.084324 & $-0.041175^{*}$ & 0.089335 \\
\hline
\end{tabular}

*Signifikan pada taraf nyata $10 \%$.

Berdasarkan Tabel 2, diperoleh bahwa volume perdagangan tidak mempengaruhi volatilitas untuk saham CPIN, ICBP dan UNVR, sehingga tidak cukup bukti untuk mendukung teori MDH pada pasar.

\section{4 Hasil Implementasi Model Kausalitas Granger}

Perilaku peubah ekonomi dalam kenyataan memiliki hubungan satu arah maupun dua arah (konsep kausalitas). Hubungan kausalitas dapat diuji dengan menggunakan uji kausalitas Granger 
(Juanda B dan Junaidi : 2012: 145). Uji kausalitas Granger hanya melibatkan variabel stasioner (Enders W : $2015: 384$ ).

\subsubsection{Uji Stasioner}

Uji Augmented Dickey Fuller (ADF test) adalah uji formal untuk memeriksa kestasioneran data. Hasil dari uji stasioner data menunjukkan bahwa semua variabel stasioner pada level dengan taraf nyata $10 \%$ untuk semua saham kecuali volume perdagangan pada saham MNCN. Volume perdagangan pada saham MNCN tidak stasioner pada level, tetapi stasioner pada diferensiasi pertama (berordo 1).

\subsubsection{Hubungan Kausal Granger antara Volume Perdagangan, Bid-Ask Spread, Return Saham dan Volatilitas}

Model hubungan kausal antara volume perdagangan, bid-ask spread dan return saham terhadap volatilitas disajikan pada persamaan (2), persamaan (3), persamaan (4), persamaan (5), persamaan (6) dan persamaan (7). Semua variabel perdagangan yang digunakan pada pengujian kausalitas Granger adalah data deret waktu dengan derajat integrasi 0 atau ditulis $\mathrm{I}(0)$ pada semua saham kecuali saham MNCN. Semua variabel perdagangan saham yang digunakan pada pengujian kausalitas Granger pada saham MNCN adalah data deret waktu dengan derajat integrasi 1 atau ditulis I(1). Hasil pengujian kausalitas Granger pada hubungan antara volume perdagangan, bid-ask spread dan return saham terhadap volatilitas dapat dilihat pada Tabel 3.

Tabel 3 Uji kausalitas Granger pada hubungan antara volume perdagangan, bid-ask spread, return saham terhadap volatilitas

\begin{tabular}{|c|c|c|c|c|c|c|}
\hline \multirow[b]{2}{*}{ Kode Saham } & \multicolumn{2}{|c|}{$V_{t} \leftrightarrow \sigma_{t}$} & \multicolumn{2}{|c|}{$S_{t} \leftrightarrow \sigma_{t}$} & \multicolumn{2}{|c|}{$R_{t} \leftrightarrow \sigma_{t}$} \\
\hline & $V_{t} \stackrel{G C}{\rightarrow} \sigma_{t}$ & $\begin{array}{l}\sigma_{t} \\
\stackrel{G C}{\rightarrow} V_{t}\end{array}$ & $S_{t} \stackrel{G C}{\rightarrow} \sigma_{t}$ & $\begin{array}{l}\sigma_{t} \\
\stackrel{G C}{\rightarrow} S_{t}\end{array}$ & $R_{t} \stackrel{G C}{\rightarrow} \sigma_{t}$ & $\sigma_{t} \stackrel{G C}{\rightarrow} R_{t}$ \\
\hline AALI & $\sqrt{ }$ & - & - & - & $\sqrt{ }$ & - \\
\hline ASRI & $\sqrt{ }$ & - & - & - & $\sqrt{ }$ & $\sqrt{ }$ \\
\hline BMRI & $\sqrt{ }$ & - & $\sqrt{ }$ & - & $\sqrt{ }$ & - \\
\hline CPIN & $\sqrt{ }$ & - & - & - & $\sqrt{ }$ & $\sqrt{ }$ \\
\hline ICBP & $\sqrt{ }$ & - & $\sqrt{ }$ & $\sqrt{ }$ & $\sqrt{ }$ & $\sqrt{ }$ \\
\hline INDF & $\sqrt{ }$ & - & $\sqrt{ }$ & - & - & - \\
\hline JSMR & $\sqrt{ }$ & - & - & - & - & $\sqrt{ }$ \\
\hline KLBF & $\sqrt{ }$ & - & $\sqrt{ }$ & - & $\sqrt{ }$ & - \\
\hline LPKR & $\sqrt{ }$ & - & $\sqrt{ }$ & - & - & - \\
\hline $\mathrm{MNCN}^{*}$ & $\sqrt{ }$ & - & - & - & $\sqrt{ }$ & - \\
\hline SMGR & $\sqrt{ }$ & - & - & - & $\sqrt{ }$ & $\sqrt{ }$ \\
\hline
\end{tabular}


STATMAT

(Jurnal Statistik dan Matematika)

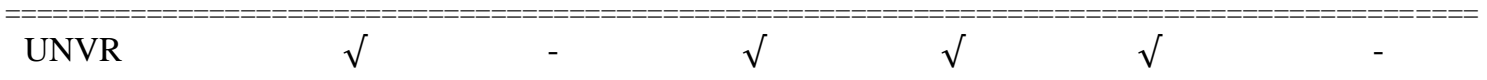

GC : Granger-Cause

$\sqrt{ }$ : terdapat hubungan kausal yang signifikan pada level $10 \%$

* : menggunakan data pada diferensiasi pertama.

Berdasarkan Tabel 3, terjadi hubungan kausalitas satu arah antara volume perdagangan dan volatilitas untuk semua saham. Karena semua saham yang diteliti hanya terdapat hubungan satu arah, maka tidak cukup bukti untuk mendukung berlakunya teori SIAH. Hal ini menimbulkan dugaan bahwa perdagangan intraday sampel saham LQ-45 cenderung mengikuti teori MDH.

Berdasarkan Tabel 3, terjadi hubungan kausalitas dua arah antara bid-ask spread dan volatilitas pada saham ICBP dan UNVR. Berdasarkan Tabel 3, terjadi hubungan kausalitas dua arah antara return saham dan volatilitas pada saham ASRI, CPIN, ICBP, dan SMGR.

Uji kausalitas Granger pada hubungan antara volume perdagangan, bid-ask spread dan return saham disajikan pada Tabel 4.

Tabel 4 Uji kausalitas Granger pada hubungan antara volume perdagangan, bid-ask spread dan return saham

\begin{tabular}{lcccccc}
\hline Kode Saham & \multicolumn{2}{c}{$S_{t} \leftrightarrow V_{t}$} & \multicolumn{2}{c}{$R_{t} \leftrightarrow V_{t}$} & \multicolumn{2}{c}{$R_{t} \leftrightarrow S_{t}$} \\
\cline { 2 - 7 } & $S_{t} \stackrel{G C}{\rightarrow} V_{t}$ & $V_{t} \stackrel{G C}{\rightarrow} S_{t}$ & $R_{t} \stackrel{G C}{\rightarrow} V_{t}$ & $V_{t} \stackrel{G C}{\rightarrow} R_{t}$ & $R_{t} \stackrel{G C}{\rightarrow} S_{t}$ & $S_{t} \stackrel{G C}{\rightarrow} R_{t}$ \\
\hline AALI & - & - & - & $\sqrt{ }$ & - & - \\
ASRI & - & - & $\sqrt{ }$ & - & - & - \\
BMRI & - & $\sqrt{ }$ & - & - & - & - \\
CPIN & - & - & - & $\sqrt{ }$ & - & - \\
ICBP & - & - & - & - & - & - \\
INDF & - & - & - & - & - & - \\
JSMR & - & - & - & - & - & $\sqrt{ }$ \\
KLBF & - & - & $\sqrt{ }$ & $\sqrt{ }$ & - & - \\
LPKR & - & $\sqrt{ }$ & - & - & - & $\sqrt{ }$ \\
MNCN $*$ & - & - & - & - & - & - \\
SMGR & - & - & - & - & - & - \\
UNVR & $\sqrt{ }$ & - & - & - & - & - \\
\hline
\end{tabular}

GC : Granger-Cause

$\sqrt{ }$ : terdapat hubungan kausal yang signifikan pada level $10 \%$

* : menggunakan data pada diferensiasi pertama. 
(Jurnal Statistik dan Matematika)

Berdasarkan Tabel 4, tidak terjadi hubungan kausalitas dua arah antara bid-ask spread dan volume perdagangan untuk semua saham. Terjadi hubungan kausalitas dua arah antara return saham dan volume perdagangan untuk saham KLBF. Tidak terjadi hubungan kausalitas dua arah antara return saham dan bid-ask spread untuk semua saham.

\section{KESIMPULAN}

Berdasarkan hasil regresi, diperoleh bahwa tidak cukup bukti untuk mendukung teori MDH pada pasar. Berdasarkan kausalitas Granger, tidak cukup bukti untuk mendukung berlakunya teori SIAH. Hal ini menimbulkan dugaan bahwa perdagangan intraday sampel saham LQ-45 cenderung mengikuti teori MDH.

\section{DAFTAR PUSTAKA}

Aden. 2018. Analisis Komparasi Estimasi Jumlah Penjualan Produk Dengan Metode Eksponensial Tunggal Pendekatan Adaptif Dan Metode Eksponensial Ganda Dua Parameter Dari Holt. Jurnal Saintika Unpam. Vol. 1, No. 1. 1-19.

Enders W. 2015. Applied Econometric Time Series. New York: John Wiley and Sons, Inc.

Juanda B, Junaidi. 2012. Ekonometrika Deret Waktu. Bogor (ID): IPB Press.

Paital RR, Sharma NK. 2016. Bid-Ask Spreads, Trading Volume and Return Volatility. Eurasian Journal of Economics and Finance. Vol. 4. No.1. 24-40.

Tandelilin E. 2010. Portofolio dan Investasi Teori dan Aplikasi. Yogyakarta (ID): Kanisius.

Valentika N, Nugrahani E, Lesmana D. 2017. Modeling Contemporaneous and Causal Relationships of Stock Trading Variables (Case Study of Indonesian Stock Exchange on LQ45 Index). International Journal of Engineering and Management Research. Vol. 7. No.6. 146-151. 